\title{
LA REPRESENTACIÓN LITERARIA DE LO MONSTRUOSO EN LA OBRA DRAMÁTICA DE VALLE-INCLÁN
}

Norman Marín Calderón

\section{(c) $(7)(9)$}

Esta obra está bajo una licencia Creative Commons 



\title{
LA REPRESENTACIÓN LITERARIA DE LO MONSTRUOSO EN LA OBRA DRAMÁTICA DE VALLE-INCLÁN
}

\section{THE LITERARY REPRESENTATION OF MONSTROSITY IN VALLE- INCLÁN'S DRAMATIC WORK}

Norman Marín Calderón

\begin{abstract}
RESUMEN
El esperpento es una técnica literaria creada por Ramón del Valle-Inclán la cual se distingue por examinar una deformación sistemática de la realidad, acentuando sus atributos grotescos, feos, monstruosos e incoherentes ahí donde los animales y las cosas se humanizan mientras que los seres humanos se animalizan. También, el esperpento constituye una manera de vislumbrar el mundo y de desenmascarar la realidad. Este análisis esperpéntico se realiza tomando en cuenta las obras valleinclanesas Luces de Bohemia (1920) y Divinas palabras (1920).

Palabras clave: esperpento, monstruoso, grotesco, deformidad, Valle-Inclán.
\end{abstract}

\begin{abstract}
The esperpento (fright, nonsense, macabre) is a literary technique created by Ramón del ValleInclán which consists of examining a systematic deformity of reality, accentuating its grotesque, ugly, monstrous and incoherent features where animals and objects are humanized whilst human beings are animalized. Likewise, the esperpento constitutes a way of foreseeing the world and unmasking reality. This grotesque analysis is done taken into consideration Valle-Inclán's Lights of Bohemia (1920) and Divine Words (1920).
\end{abstract}

Key words: esperpento (fright, nonsense, macabre), monstrous, grotesque, deformity, Valle-Inclán.

La imagen más bella es absurda en un espejo cóncavo. Ramón María del Valle-Inclán

\section{Introducción}

El esperpento es una técnica estética creada por el escritor español Ramón del ValleInclán (1866-1936), la cual se distingue por examinar cierta deformación sistemática de la realidad, acentuando sus atributos grotescos, monstruosos e incoherentes. En este sentido, el presente

Dr. Norman Marín Calderón. Universidad de Costa Rica. Profesor de las escuelas de Lenguas Modernas y de Filología, Lingüística y Literatura. Costa Rica.

Correo electrónico: normanmarin@hotmail.com

Recepción: 15- 12- 2014

Aceptación: 19- 06- 2015 
ensayo explora la tesis de que la técnica esperpéntica es una manera estética/literaria de ahondar en los rasgos monstruosos de la vida cotidiana (española). Así, los personajes del ciclo esperpéntico son seres segregados, lóbregos o deformes. Igualmente, el autor esperpéntico funge como un demiurgo quien interviene en la situación caótica, poblándola de lo grotesco y estructurándola como un trastorno.

De igual manera, el esperpento constituye una forma de vislumbrar el mundo y de desenmascarar la realidad. El proceso esperpéntico toma lugar gracias al uso de diferentes técnicas dramáticas, tales como, su naturaleza tragicómica, el aire carnavalesco de su trama, el desdoblamiento de los personajes, el uso de la máscara, la distorsión del lenguaje, así como la "muñequización" o la "animalización" de algunos de sus personajes. Este análisis de lo monstruoso se realizará a partir de la obra valleinclanesca Divinas palabras (1920) y su referencia de origen en Luces de Bohemia (1920).

\section{Una teoría del esperpento}

Ramón del Valle-Inclán, quien, según Pedro Salinas, es el hijo pródigo de la Generación del 98, se convirtió desde entonces en uno de los escritores españoles más prolíficos de principios del siglo XX, sobre todo, al reconocer la trascendencia de su composición estética literaria denominada el esperpento. Valle-Inclán critica la sociedad de su tiempo por medio de una literatura que permite denunciar su hipocresía y egoísmo. El esperpento se debe entender aquí como un método deconstructivo que posibilita la deformación de la realidad circundante para al mismo tiempo, mostrar lo absurdo de la sociedad en general.

Valle-Inclán toma el concepto de esperpento de la producción artística de Francisco de Goya (1746-1828) y de la literatura satírico-moral de Francisco de Quevedo (1580-1645), sin embargo, la conceptualización de esta técnica emergió literalmente en la escena duodécima de su obra Luces de Bohemia (1920). Max Estrella, el protagonista de la obra, propone una definición del término "esperpento":

\footnotetext{
MAX. Los héroes clásicos reflejados en los espejos cóncavos dan el Esperpento. El sentido trágico de la vida española solo puede darse con una estética sistemáticamente deformada. [...] Las imágenes más bellas en un espejo cóncavo son absurdas. [...] La deformación deja de serlo cuando está sujeta a una matemática perfecta. Mi estética actual es transformar con matemática de espejo cóncavo las normas clásicas. Deformemos la expresión en el mismo espejo que nos deforma las caras y toda la vida miserable de España. (Valle-Inclán, 1999, p. 98)
}

De acuerdo con lo declarado por el poeta Max Estrella, el esperpento consiste en un proceso de deformación de la realidad que propone una caricaturización sustentada de la existencia humana, por medio de un discurso coloquial, usualmente muy violento y mordaz, el cual se basa en la mutación de ciertos personajes convertidos en marionetas de la vida.

Por su parte, de acuerdo con el Diccionario de la Real Academia Española (DRAE), el esperpento, vocablo de origen incierto, se anuncia de la siguiente manera:

Esperpento. 1. $m$. Hecho grotesco o desatinado. 2. $m$. Género literario creado por Ramón del Valle-
Inclán, escritor español de la Generación del 98, en el que se deforma la realidad, recargando sus rasgos
grotescos, sometiendo a una elaboración muy personal el lenguaje coloquial y desgarrado. 3. m. coloq.
Persona o cosa notable por su fealdad, desaliño o mala traza. (DRAE, 2001, p. 978)

El concepto dramático de esperpento fue concebido por su creador con el fin de exponer el verdadero sentido trágico de la vida, y así, no olvidar que la existencia está teñida de aspectos grotescos, absurdos y monstruosos. Esta técnica obliga al espectador/lector a asumir 
una nueva posición subjetiva ante el mundo que se desmorona ante sus ojos. Aquí es donde el espejo cóncavo permite la distorsión de la imagen: los personajes del ciclo esperpéntico son distinguidos como sujetos marginales, lóbregos y repugnantes quienes, a su vez, poseen la sagacidad del docto bufón. El monstruoso efecto de lo esperpéntico enaltece la superación del absurdo y del fracaso de la sociedad. El esperpento deforma la realidad para mostrar que está infectada por el mal y el desarreglo. Aquí el autor-dramaturgo se convierte en ese demiurgo que retoza con el caos del mundo y lo configura a su antojo, para luego presentárselo descarnado a su audiencia.

Según Valle-Inclán, el esperpento condensa la amplia raigambre de lo grotesco. Parte inherente de la tradición grotesca se encuentra el rasgo de la distorsión. Es un lugar ominoso en donde se exalta una situación familiar que deviene, de repente, en siniestra. Según Cardona y Zahareas, la distorsión acaecida en la situación esperpéntica conlleva

\footnotetext{
[...] el de la fusión de formas humanas y animales, y el de la combinación del mundo de la realidad con el de la pesadilla. Estos efectos extraños mueven al espectador a la risa, al horror y a la perplejidad, siendo así que frecuentemente la risa sirve para aminorar el horror y la perplejidad, y para que la pesadilla se haga más llevadera (Cardona y Zahareas, 1970, p. 46)
}

Por ende, el foco fundamental del aspecto grotesco del esperpento es la técnica de la distorsión que convierte en risa aquello que espanta a la vez que el horror de la existencia se disfraza de lo cómico y divertido. Esto es tragicomedia, después de todo.

Una de las características principales de esta técnica consiste en trasformar a los personajes en títeres, muñecos o fantoches. Los seres humanos del esperpento son maniquíes porque sugieren, de modo sistemático, una desviación tajante e inquietante de las cosas que son familiares a la raza humana:

\footnotetext{
Por su cuerpo pequeño, el títere es un símbolo eficaz de la pequeñez espiritual del hombre, de la ausencia de la autenticidad: la divergencia entre lo que se dice que el hombre es y lo que es en realidad. Pero, lo que determina el impacto grotesco, no obstante, es la forma en que el autor maneja el títere (Cardona y Zahareas, 1970, p. 49)
}

En fin, el uso de las marionetas, maniquíes y figurillas le permite al autor presentar a un ser humano que duda de lo que significa realmente ser un hombre-en-el-mundo ahí donde se encumbra el sentido absurdo de la vida puesto que el sujeto humano no es más que un ser mecánico, deshumanizado, es decir, un títere monigote.

De igual manera, las deformaciones promovidas por el esperpento aquejan tanto a personajes como a ambientes escénicos: la mayoría de escenarios donde deambula el esperpento toma lugar en cantinas, prostíbulos, antros ilícitos de apuesta, tugurios, casas miserables, en el lado licencioso de ferias gallegas o en las calles oscuras de Madrid. Por su parte, los personajes favoritos del esperpento son los borrachos, las prostitutas, los indigentes, artistas bohemios fracasados así como sujetos rebajados a la posición de marionetas o de animales o, aún más, a meros objetos inanimados -personas hechas cosas... o nada-.

La técnica esperpéntica se ubica en el centro entre dos márgenes: la tragedia y el desvarío. De alguna manera, el esperpento no es una estética trágica mucho menos cómica, es, más bien, "tragicómica", o incluso, algunos la denominan "tragi-fársica". De una u otra manera, el mismo Max Estrella insistía que "la tragedia nuestra no era tragedia" (Valle-Inclán, 1999, p. 39). Como tal, el esperpento funciona como una poética "expresionista" que capta detalladamente circunstancias y personajes de manera satírica, sarcástica, con humor negro, y usualmente de manera irascible. En una entrevista con Gregorio Martínez Sierra, Valle-Inclán explica lo siguiente: 


\begin{abstract}
Comenzaré por decirle a usted que creo que hay tres modos de ver el mundo artística o estéticamente: de rodillas, en pie o levantado en el aire. Cuando se mira de rodillas - y ésta es la posición más antigua en literatura-, se da a los personajes, a los héroes, una condición superior a la condición humana, cuando menos a la condición del narrador o del poeta. [...] Hay una segunda manera, que es mirar a los protagonistas novelescos como de nuestra propia naturaleza, como si fueran nuestros hermanos, como si fuesen ellos nosotros mismos, como si fuera el personaje un desdoblamiento de nuestro yo, con nuestras mismas virtudes y nuestros mismos defectos. [...] Y hay otra tercera manera, que es mirar al mundo desde un plano superior, y considerar a los personajes de la trama como seres inferiores al autor, con un punto de ironía. Los dioses se convierten en personajes de sainete. Esta es una manera muy española, manera de demiurgo, que no se cree en modo alguno hecho del mismo barro que sus muñecos. [...] Y esta consideración es la que me llevó a dar un cambio en mi literatura y a escribir los esperpentos, el género literario que yo bautizo con el nombre de esperpentos. (Marínez-Sierra, 1928, pp. 3-4)
\end{abstract}

En esta entrevista, Valle-Inclán asegura que su poética del esperpento tiene también su génesis en la literatura picaresca de Francisco de Quevedo y en la pintura decadentista de Francisco de Goya. En su Vida, llega a decir que "yo considero también mis personajes inferiores a mí. Mi obra es un intento de lo que quise hacer" (Valle-Inclán, 1928, p. 104). Para Valle-Inclán, su esperpento es más que una caricatura consecuente de la realidad, es la representación contundente de esta, donde el papel del dramaturgo es la de un demiurgo, a saber, la de ser un creador absoluto. De allí la persistente manipulación a sus personajes.

\title{
3. Una lectura esperpéntica de Divinas palabras
}

Divinas palabras (1920), subtitulada Tragicomedia de aldea, es considerada una obra valleinclanesca de "transición", es decir, un texto que introduce, por vez primera en el desarrollo estético de Ramón del Valle-Inclán, las características incipientes de la técnica del esperpento. Inicialmente, la creación de esta estética despunta a partir de la situación social que experimenta la zona rural de la Galicia de principio del siglo XX. De hecho, el esperpento en Divinas palabras funciona como la estrategia idónea para denunciar, de manera clínica, un mundo gallego moralmente impasible en donde se descubren actos de inhumanidad y crueldad que perpetran algunos gallegos de la época: aquí el esperpento sirve como instrumento de denuncia y exploración de la realidad de la zona rural de Galicia, y España en general. Es así que el esperpento funciona en Divinas palabras con el solo fin de radiografiar la realidad envilecida y corrupta de los gallegos rurales de entonces, a partir de los temas del adulterio, la lujuria, la inmoralidad, la avaricia, la hipocresía, el incesto y la homosexualidad perversa, entre otros.

En general, se podría declarar que Divinas palabras es una tragicomedia rural compuesta en torno a Laureano, un enano idiota hidrocéfalo quien, debido a su grotesca apariencia y chocante manera de vivir, eslabona todas las escenas esperpénticas de la obra dramática. La obra es una composición teatral organizada en tres jornadas con diferentes escenas cada una. Así las cosas, en la primera jornada el espectador/lector se da cuenta que la madre del "Idiota" -Juana la Reina- gana dinero explotándolo comercialmente, cuando lo exhibe como un adefesio fenómeno en ferias, tabernas y otros tipos de meandros. Al morir la madre, los hermanos de esta -Pedro Gailo y Marica del Reino-disputan la posesión y custodia del hidrocéfalo para seguir lucrándolo en ferias y celebraciones rurales. Primero, Mari-Gaila, esposa de Pedro Gailo, quien es el sacristán de la Parroquia de San Clemente, arrebata al Idiota y huye de su hogar para seguir explotándolo y hacer dinero. En una de esas ferias de temporada, Mari-Gaila abandona al Idiota en una cantina para ir a fornicar con un bandolero 
llamado Séptimo Miau. En dicha taberna, un homosexual degenerado -Miguelín el Padronésobliga a beber en demasía al Idiota mientras los concurrentes se divierten con el espectáculo grotesco que brinda el Fenómeno. De tal exceso, el Idiota muere mientras la infame Mari-Gaila finge aflicción por la muerte de este.

La última jornada se abre con el cadáver del Idiota yaciendo sobre la calle, el cual, durante la noche, y por negligencia de Mari, fue devorado por unos cerdos. Luego, los parroquianos "generosamente" exponen el cuerpo grotesco de Laureano ante la iglesia con el fin de recaudar dinero para su sepelio. En ese momento, Mari-Gaila es descubierta por el pueblo nuevamente fornicando con su amante Miau en las profundidades del campo gallego. Acechada por perros furiosos y gente furibunda de la aldea, le exigen despojarse de sus ropas para luego llevarla a la iglesia para apedrearla por adúltera. En ese momento, entra su esposo, el sacristán, quien se lanza desde el campanario para proclamar las "divinas palabras" (perícopa de la adúltera) que Cristo pronunció ante aquellos que deseaban lapidar a la amancebada: "El que de ustedes esté sin pecado sea el primero en arrojar la piedra contra ella”. Así, el conjuro del pasaje latino -las divinas palabras- disuade a los irascibles aldeanos del linchamiento a la mujer.

Parte de la riqueza estética y temática de Divinas palabras se encuentra en el desarrollo de sus personajes y la constitución que hace de ellos el autor, a través de la didascalia. El primero de estos personajes es Laureano, el Idiota. Algunos críticos de la obra de Valle-Inclán aseveran que lo horripilante de la inmoralidad de los gallegos de la época es reforzado por el afeamiento que reintegra la figura chocante de Laureano. El dramaturgo se asegura de presentar a un ser horrendo quien es referido como

\footnotetext{
el idiota [que] agita las manos con temblor de epilepsia, y pone los ojos en blanco. [...] El Idiota, [con] los ojos vueltos y la lengua muerta entre los labios negruzcos, respiraba con ahogado ronquido. La enorme cabeza, lívida, greñuda, viscosa, rodaba en el hoyo como una cabeza cortada (II, 7, 86)
}

El aspecto monstruoso del Idiota promueve cierta técnica de animalización en la obra donde la figura de Laureano se rebaja a la categoría de bestia. El autor representa al Idiota con una enorme cabeza bamboleándose en el zarandeo del carretón en movimiento, y quien es también un blanco perfecto para las moscas que reposan sobre sus labios o su frente, cubriéndole casi toda la cabeza.

A lo largo de la obra, algunos animales aparecen en escena para evidenciar la bestialidad de Laureano. Por ejemplo, hay una perra, Coimbra, quien se acerca a Laureano para ladrarle porque le huele a "muerto": "Lentamente el animal [Coimbra] se dobla, y agacha la cola aullando con el aullido que reservan los canes para el aire de muerto" (I, 1, 17). Es más, Laureano se rebaja a la categoría de animal cuando entabla cierta conversación con los sapos: [...] y el Idiota, balanceando la cabeza enorme sobre la almohada de paja, da su grito en la humedad
del cementerio.

EL IDIOTA. ¡Hou! ¡Hou!

EL SAPO. ¡Cro! ¡Cro!” (I, 5, 45)

Si los sapos departen con Laureano, los cerdos no le hablan sino que se lo almuerzan. Su explotadora, Marica del Reino, lo describe así: “AAquí tenéis este cuerpo frío [el de Laureano]! ¡Cara y manos le comieron los cerdos! ¡Duélense las entrañas, la vista se duele viendo esta carnicería! ¡Testigo sois! ¡Comido de las bestias!” (II, 10, 101). 
Efectivamente, uno de los retratos más espantosos de Divinas palabras se observa en el momento cuando muere Laureano. Ahí se expone el cuerpo inerte para que los transeúntes, ante tal espectáculo, puedan darle limosna para colaborar con su entierro. Nuevamente, Laureano es el objeto de la codicia y medio para hacer dinero fácil. La didascalia es contundente con respecto a uno de los actos más grotescos y horripilantes de la obra:

\section{La enorme cabeza del idiota destaca sobre una almohada blanca, coronada de camelias, la frente de cera. Y el cuerpo rígido dibuja su desmedrado perfil bajo el percal de la mortaja azul con esterillas doradas. Encima del vientre, inflamado como el de una preñada, un plato de peltre lleno de calderilla recoge las limosnas, y sobrenada en el montón de cobre negro una peseta luciente. (III, 3, 118)}

La acotación también indica que las moscas yacen sobre su cara deformada y que la hediondez del cuerpo putrefacto de Laureano se encumbra hasta revolverse con el aroma divino del incienso que brota de la iglesia románica de San Clemente. Esta antítesis entre lo bienoliente del incienso y lo desagradable del cuerpo pútrido confirma, una vez más, el aspecto absurdo y monstruoso de la técnica del esperpento.

Otro personaje que colabora con la particularidad repugnante de Divinas palabras es el sacristán Pedro Gailo. Pedro es descrito como el resultado de la aleación entre un hombre débil y un fantoche: sujeto ridículo y moralmente degenerado cuya honra ha sido mancillada públicamente por el adulterio de su esposa, Mari-Gaila. Las mismas acotaciones lo describen como "un viejo fúnebre, amarillo de cara y manos, barbas mal rapadas, sotana y roquete" $(\mathrm{I}, 1,13)$ y "con las barbas grises sin afeitar y las mejillas cavadas, el sacristán tiene algo que recuerda la llama amarilla de los cirios" (II, 4, 67). En definitiva, el rasgo esperpéntico del sacristán reside fundamentalmente en su repugnancia física así como moral. Tanto sus acciones dramáticas como sus descripciones didascálicas contribuyen a que el Cornudo se convierta en un ser esperpéntico y títere de sus circunstancias -hombre sin virilidad y cruelmente avaro.

De hecho, el aspecto físico del cornudo sacristán es presentado en la obra como grotesco. Se muestra al personaje como un pelele o un fantoche. Esto se puede prever en la manera en que el dramaturgo presenta al fantoche: el personaje no dice mucho, y casi siempre guarda silencio. Las que se encargan de hablar por él son las acotaciones mismas. Esto revela su pasividad y mediocridad que constituyen también características relevantes de la estética del esperpento. En este sentido, el sacristán es un títere. Según D. Dougherty, un títere

\footnotetext{
es un signo potente de la mecanización del individuo, de la pérdida de su dignidad humana y la consecuente incapacidad de luchar contra una nueva fatalidad, impuesta ya no por los dioses sino por los códigos culturales heredados del pasado o por las leyes socioeconómicas del estado moderno (Dougherty, 2008, p. 485)
}

La caracterización esperpéntica del sacristán se puede distinguir a partir del clásico dilema de defender su honra ante las infidelidades de su esposa. Pedro Gailo es un ser cobarde y aprensivo. Sabe de los lances licenciosos de su mujer pero no defiende su honra. La labor monstruosa del sacristán en la obra se apuntala, de manera precisa, con la escena incestuosa en que invita a su hija Simoniña a unírsele en la cama. Ya de entrada, la misma Simoniña es descrita como una muchacha fea y desagradable: "La hija [Simoniña], abobada, lechosa, redonda con algo de luna, de vaca y de pan" (I, 3, 30). Esta descripción chocante del físico de la niña precipita la impresión esperpéntica que abre la escena del incesto: Sin gritar, sin llorar, ni oponerse, Simoniña muy naturalmente no le hace caso al padre, sino, más bien, le ofrece tomar un trago para que se duerma y la deje de "molestar". No obstante, cuando la niña le acerca el vaso para darle de beber al padre ebrio, se aproxima de tal manera que sutilmente ella lo incita con su cuerpo semidesnudo: 
PEDRO GAILO. ¡Ven, Simoniña! ¡Ven, prenda! Pues que me da corona, vamos nosotros dos a ponerle otra igual en la frente [a Mari-Gaila]. ¿Dónde estás, que no te palpo? Ahora tú eres mi reina. Si coceas, no lo eres más. Le devolvemos su mala moneda. ¡Cómo ríe aquel demonio colorado! ¡Vino a ponérseme encima del pecho! ¡Tórnamelo, Simoniña!... ¡Prenda! ¡Espántamelo! (II, 6, 81)

Con respecto a esta escena, comenta Greenfield (1972) que

el sacristán no puede hacer nada respecto a la promiscuidad de su mujer, y su naturaleza [inferior] no le permite pagarle con la misma moneda, por lo menos no con premeditación. El vino le da la voluntad, y la proximidad de su hija el pensamiento (Greenfield, 1972, p. 162)

De aquí en adelante, se puede advertir a un sacristán religioso pero moralmente monstruoso e impasible, un verdadero títere incestuoso del esperpento.

Si el Idiota y el fantoche son seres esperpénticos en tanto son sujetos feos, grotescos y desagradables, Mari-Gaila y Séptimo Miau, la pareja adúltera, lo son por sus infames características morales y espirituales: los primeros poseen físicos repugnantes mientras que los segundos lo develan al nivel de su conciencia. De hecho, el efecto esperpéntico de la obra se solidifica, una vez más, gracias a la caracterización de Mari-Gaila y Séptimo Miau. Primeramente, Mari-Gaila contrasta con su marido el sacristán. Mientras el sacristán es descrito como "un viejo fúnebre, amarillo de cara y manos, [...] con barbas grises sin afeitar y las mejillas cavadas" (pp. 13 y 67), Mari-Gaila es retratada por su delectación y gracia erótica, por ser "armónica en los ritos del cuerpo y de la voz" (I, 3, 30), de hecho es "rítmica y antigua, adusta y resuelta, [quien] levanta su blanca desnudez ante el río cubierto de oros" (III, 4, 131). De esta manera, y muy contrariamente a su esposo, Mari-Gaila encarna las insignias de la belleza, el poder y la seducción ahí donde adquiere un carácter trascendental cuando se opone al fachoso de su marido. En todo caso, la amoralidad de la adúltera aparece siempre mitigada por su brío y su hermosura, si bien los seudovalores de Mari siempre degeneran en egoísmo, codicia y libertinaje sexual.

De hecho, la adúltera sacristana encarna la ignorancia moral y el descalabro espiritual de la obra. Es una mujer bella y seductora quien es egoísta y antojadiza a la vez. Le importan poco los demás, y solo se preocupa por sí misma. No atiende a su marido e hija porque solo se concentra en ella y su bienestar. A veces finge ser cándida e ilusa, cuando, de repente, se torna perspicaz y oportunista. Su fingimiento es sobresaliente en tanto emplea el recurso de la hipocresía para obtener lo que más quiere en este mundo, a saber, dinero y placer sexual.

Mari-Gaila representa entonces eso que siendo bello y luminoso en el exterior, encubre la monstruosidad interior de un sujeto dedicado al disfrute de las pasiones más bajas. Este personaje físicamente atractivo, mas denigrado espiritualmente, funciona como un agente comparador con las otras mujeres de la obra dramática.

Así, mientras Mari-Gaila es retratada como un ser libidinoso y encantador, las otras mujeres llevan lo horroroso en sus caras y sus cuerpos, pintándolas con una fealdad física que produce la mayor de las repulsiones. Por ejemplo, Marica del Reino es descrita como una "mujeruca" "raída y pelona, [...] con el refajo mal ceñido, y los pechos de cabra seca fuera del justillo" (pp.99-100). Por su parte, la vieja mendiga, Rosa la Tatula, es dibujada como una mujer vieja, "encorvada, [y] sin dientes" (p. 108). En la misma categoría se ubica Simoniña que es una muchacha "abobada, lechosa" y muy gorda, como una vaca (p. 30). De esta manera, si el esperpento producido por las mujeres de Divinas palabras se percibe a través de lo grotesco visual y su repelente apariencia, Mari-Gaila trae lo esperpéntico a escena justamente porque repugna por su conciencia monstruosa y vil. 
Junto a Mari-Gaila, otro de los personajes que se destaca por lo esperpéntico de su espíritu, y no tanto por su apariencia física, lo constituye el Compadre Miau, quien es conocido por sus muchos sobrenombres: el farandul (farandulero), Lucero, el Conde Polaco, Séptimo Miau, o simplemente Miau. En primer lugar, Séptimo Miau representa la antítesis de Pedro Gailo: mientras el cornudo sacristán simboliza la soledad y el encierro (el campo de lo sedentario y la iglesia), Miau personifica la idea de libertad y emancipación (la trashumancia). Miau es un delincuente de larga trayectoria que se dedica a la vida nómada para así huir de las autoridades que lo persiguen por sus múltiples crímenes.

De igual forma, Séptimo Miau se percibe como un "don Juan” quien se jacta de sus buenas apariencias y su capacidad de seducir a las mujeres. Ya tiene una manceba -Poca Pena- y se sabe de otra amante que consigue en un pueblo -Mari-Gaila, la esposa infiel del cornudo sacristán de San Clemente-. Dicen los chismes pueblerinos que Miau tiene un pacto con el diablo, y quien es capaz de cualquier cosa ya que no tiene escrúpulos. Y es, quizás, esta característica la que, muy en el fondo, seduce a Mari-Gaila para sostener sus relaciones extramatrimoniales. Se dice, al respecto, que

\footnotetext{
Mari-Gaila elige como compañero de adulterio a un hombre que, a sus ojos, posee un atractivo, basado en cualidades y posibilidades antitéticas a las de su marido: goza de éxito entre las mujeres, está rodeado de misterio, disfruta de cierto prestigio en su entorno y le ofrece la expectativa de una vida libre e independiente (Baamonde-Traveso, 2006, p. 21)
}

En definitiva, Divinas palabras es una obra dramática del esperpento la que se sirve de todos sus personajes para resaltar la naturaleza grotesca, absurda y monstruosa de la España (gallega) finisecular. Así como los principales, los personajes menores también favorecen la difusión de la visión esperpéntica en el argumento de la obra. Por ejemplo, Miguelín el Padronés, el chalán, es un sujeto esperpéntico justamente por exhibir su inmoralidad y depravación a lo largo de la obra. Es retratado como un hombre gordo "que anda en caminos, al cual por sus dengues le suele acontecer en ferias y mercados que lo corran y afrenten" (I, 2, 23), "Miguelín se busca con la lengua un lunar rizoso que tiene a un canto de la boca [...]" (pp. 24-25). Es quien paga por los tragos que matan a Laureano, y es el encargado de hacerle saber a la aldea que Mari-Gaila y Miau están fornicando en las afueras del pueblo. El Padronés es un hombre maldiciente, depravado y acusado de ser ladrón, embustero, además de practicar la homosexualidad. En efecto, este tipo de denigración moral contribuye a desarrollar la ambientación esperpéntica, monstruosa y grotesca de Divinas palabras.

\section{Conclusión}

A pesar de lo monstruoso del código esperpéntico, existe una vía de redención que se revela al final de la obra cuando se profieren las divinas palabras que pronuncia el sacristán. Estas palabras bíblicas -enunciadas en latín- eximen al sacristán de su deshonra y dispensan a Mari-Gaila de su adulterio. En fin, la frase bíblica latina exonera a sus personajes de las consecuencias nefastas que pueda producir el esperpento en la obra, porque es la "palabra" aquella que es capaz de mudar los corazones mezquinos de la gente, en algo sublime y diferente. Así, el sin-sentido de las palabras salvadoras es, después de todo, el que produce el milagro y la transformación de un mundo tan monstruoso como el de Divinas palabras.

Cuando dichas palabras se pronuncian en español, los aldeanos se burlan de ellas y no las toman en cuenta. Mas adquieren su poder al decirlas en latín. Las divinas palabras proponen una pregunta al misterio impenetrable de la condición humana ahí donde el desconocimiento 
del latín del indocto público, promueve una lectura de lo que realmente significa el perdón y la misericordia de la vida. Al escuchar el latín, la gente de aldea acepta las sagradas palabras con sobresalto y poder. Esta vez, no cuestionan nada de ellas.

Al final, luego de la pronunciación de las todopoderosas palabras se puede observar la transformación producida por los latines: "al penetrar en la sombra del pórtico, la enorme cabeza del idiota, coronada de camelias, se le aparece [a Mari-Gaila] como una cabeza de ángel" [cursiva agregada] (III, 5, 136-137). En ese preciso momento, los personajes de Divinas palabras son redimidos por ese lenguaje incomprensible que surte sus efectos en cada uno de ellos, a partir de estas supremas palabras: "Qui sine peccato est vestrum, primus in illam lapidam mittat".

\section{Bibliografía}

Baamonde-Traveso, G. (2006). Divinas palabras, obra de transición en la dramaturgia de Valle-Inclán. Archivum. 56 (1), 7-26.

Bermejo-Marcos, M. (1971). Valle-Inclán: Introducción a su obra. Madrid: Anaya.

Cardona, R. y Zahareas, A. N. (1970). Visión del esperpento. Teoría y práctica en los esperpentos de Valle-Inclán. Madrid: Castalia.

Dougherty, D. (2008). Valle-Inclán y la tragedia moderna. Anales de la literatura española contemporánea. 33 (3), 469-500.

Greenfield, S. M. (1972). Valle-Inclán: anatomía de un teatro problemático. Madrid: Fundamentos.

Martínez-Sierra, G. (1928). Hablando con Valle-Inclán. De él y su obra. ABC. 12 (7).

Míguez-Vilas, C. (2002). Funcionalidad de las acotaciones valleinclanianas en Divinas palabras. Anales de la literatura española contemporánea. 27 (3), 738-753.

Real Academia Española. (2001). Diccionario de la Real Academia Española. (22 ed.). Madrid: Espasa.

Valle-Inclán, R. (1928). Vida. Madrid: Austral.

Valle-Inclán, R. (1966). Divinas palabras. Tragicomedia de aldea. Madrid: Espasa-Calpe.

Valle-Inclán, R. (1999). Luces de Bohemia. Madrid: Austral Clásica. 
